\title{
Level of suicidal intent predicts overall mortality and suicide after attempted suicide: a I2-year follow-up study Kirsi Suominen ${ }^{* 1,2}$, Erkki Isometsä ${ }^{1}$, Aini Ostamo ${ }^{1,3}$ and Jouko Lönnqvist ${ }^{1}$
}

\author{
Address: ${ }^{1}$ Department of Mental Health and Alcohol Research, National Public Health Institute, Helsinki, Finland, ${ }^{2}$ Jorvi Hospital, Department of \\ Psychiatry, Helsinki University Central Hospital, Espoo, Finland and ${ }^{3}$ Tampere School of Public Health, University of Tampere, Tampere, Finland \\ Email: Kirsi Suominen* - kirsi.suominen@ktl.fi; Erkki Isometsä - erkki.isometsa@ktl.fi; Aini Ostamo - aini.ostamo@ktl.fi; \\ Jouko Lönnqvist - jouko.lonnqvist@ktl.fi \\ * Corresponding author
}

Published: 20 April 2004

BMC Psychiatry 2004, 4:II
Received: 24 January 2004

Accepted: 20 April 2004

This article is available from: http://www.biomedcentral.com/ I47/-244X/4/I I

(C) 2004 Suominen et al; licensee BioMed Central Ltd. This is an Open Access article: verbatim copying and redistribution of this article are permitted in all media for any purpose, provided this notice is preserved along with the article's original URL.

\begin{abstract}
Background: The aim of this study was to comprehensively examine clinical risk factors, including suicide intent and hopelessness, for suicide and risk of death from all causes after attempted suicide over a I2-year follow-up period.
\end{abstract}

Methods: A systematic sample of 224 patients from consecutive cases of attempted suicide referred to health care in four Finnish cities between I January and 3I July 1990 was interviewed.

Results: After 12 years of follow-up $22 \%$ of these patients had died, $8 \%$ by committing suicide. The only statistically significant risk factor for eventual suicide was high scores on Beck's Suicidal Intention Scale. Male gender, older age, physical illness or disability and high scores on Beck's Suicidal Intention Scale predicted death overall.

Conclusions: Following attempted suicide, high intention to kill oneself is a significant risk factor for both death from all causes and suicide.

\section{Background}

Among the factors found to predict suicide, a previous suicide attempt is one of the strongest [1]. Suicidal intent, defined as the seriousness or intensity of the patient's wish to terminate his or her life [2], has been found to predict completed suicide in most [3-7], although not all studies [8]. Hopelessness, defined as a state of negative expectations [9], appears to be another predictor of suicide [1015]. Other factors found to associate with increased suicide risk after attempted suicide include male gender, advancing age, psychiatric disorder, previous psychiatric treatment, long-term use of hypnotics, poor physical health, living alone, and "wish to die" as a motive for the index attempt [16-18]. While both level of suicidal intent and hopelessness are likely to be significant predictors of completed suicide after a suicide attempt, their relative importance has remained unknown since few prospective studies have measured both.

The aim of the present study was to comprehensively examine clinical risk factors for suicide and other causes of death after attempted suicide, including suicidal intent and hopelessness. 


\section{Methods \\ Subjects}

A systematic sample of 224 subjects aged 15 years or more from consecutive cases of attempted suicide admitted to health care in four cities in Finland from January $1^{\text {st }}$ to July $31^{\text {st }} 1990$ was comprehensively interviewed after obtaining written informed consent [19]. The sample of the present study forms part of a database for an epidemiological monitoring project on attempted suicide in Finland. The project was carried out in collaboration with the WHO/EURO Multicentre Study on Parasuicide [20-22], which investigates factors predicting future suicidal behaviour. The repetition-prediction part of the study in Finland was carried out in four cities: Helsinki (Southern region), Jyväskylä (Central), Rovaniemi (Northern) and Seinäjoki (Western).

As parasuicide patients in Helsinki are treated in general hospitals only, the data were gathered at all five of the city's general hospitals (three university clinics and two municipal hospitals). In other regions some mild cases are treated in local health centres. In Jyväskylä, data collection was carried out at one general hospital and nine health centres, in Seinäjoki at one general hospital and six health centres, and in Rovaniemi at one general hospital and two health centres treating suicide attempters [19]. In the four research areas a total of 600 patients were asked to participate, of whom 224 (37\%) consented and completed the initial interview. The numbers of attempted suicide patients participating in the study were 114 (53 men and 61 women) in Helsinki, 33 (11 men and 22 women) in Jyväskylä, 30 (12 men and 18 women) in Rovaniemi and 47 (23 men and 24 women) in Seinäjoki. The details of the methodology have been reported earlier [19].

The WHO definition of parasuicide [23] was used, and attempted suicide and parasuicide are used as synonyms in this report. All 224 suicide attempters were interviewed according to a structured schedule, the European Parasuicide Study Interview Schedule (EPSIS I) [24].

\section{Interview schedule}

The interview form [24] contained 424 items concerning the patient's everyday life, state of health, use of alcohol and other drugs, previous suicidality, treatment in the health care system including psychiatric consultation, and life events. Beck's Suicidal Intention Scale (SIS) [2], Beck's Hopelessness Scale (HS) [9], the State Trait Anger Scale (STAS) [25], the Self Esteem Scale (SES) [26], Motives for present parasuicide (ML) $[27,28]$ and Beck's Depression Inventory (BDI) [29] were all used.

Long-standing physical illness or disability was defined as a physical illness or disability that had troubled a patient for at least one year [24]. Mental health symptoms span- ning the previous 12 months was used to define a patient's experience of prolonged periods (at least one year) of troubles within herself/himself that had hindered functioning [24]. Mental health symptoms during the past three months were categorised as on the whole poor or fair, according to the patient's evaluation of her/his mental health [24]. The assessment of lethality (somatic severity) of the suicide attempt was based on the patients' physical condition in the emergency room, the amount and type of drugs taken, and on all available information from the medical records, as in previous Finnish studies $[7,18]$. Here, three defined grades (mild, moderate and serious) were used.

\section{Outcome}

The outcome of suicide attempters, using mortality by suicide and other causes of death as the outcome criteria, was examined for a follow-up period of 12 years (1.1.199031.12.2002). The index suicide attempt was defined as first admission to the emergency unit because of suicide attempt during the study period 1.1.1990-31.7.1990. Occurrence of death data were obtained from Statistics Finland [30]. The definition of suicide was based on Finnish law for determining causes of death [31]. In every case of violent, sudden or unexpected death in Finland, the cause of death is assessed by police and medicolegal investigations involving autopsy and forensic examination.

The subjects of this study were 224 suicide attempters treated for an index suicide attempt in health care in Finland (Helsinki, Jyväskylä, Rovaniemi and Seinäjoki) during a seven-month study period in 1990.

\section{Statistical analysis}

The two-tailed chi-square test with Yates' correction, Fisher's exact test and the two-tailed t-test were employed in basic comparisons. For the survival analyses KaplanMeier and Cox regression models were used.

We analysed mortality and suicide mortality in the study population using Cox proportional hazards regression models with gender, age, number of previous suicide attempts, lethality of index attempt, Beck's Depression Inventory scores, Beck's Hopelessness Scale scores, Beck's Suicidal Intention Scale scores, physical illness or disability and use of alcohol at the time of the index attempt as covariates. The backward stepwise method (Wald) was used.

\section{Results}

By the end of the 12-year follow-up 22\% (50 out of 224) had died: $31 \%$ of male $(\mathrm{n}=31)$ and $15 \%$ of female $(\mathrm{n}=$ 19) suicide attempters (Fisher's exact test $p=0.006$ ) (Table 1). Seventeen $(8 \%)$ of the patients had committed suicide: $9(9 \%)$ of the males and $8(6 \%)$ of the females. 
Table I: Clinical and sociodemographic characteristics of 224 suicide attempters who committed suicide or not, died from all causes, or survived during the 12 -year follow-up.

\begin{tabular}{|c|c|c|c|c|}
\hline Variable & Suicide $(N=17)$ & Not suicide $(\mathrm{N}=207)$ & Death, all causes $(\mathrm{N}=50)$ & Survived $(N=174)$ \\
\hline \multicolumn{5}{|l|}{ Gender a (\%) } \\
\hline Male & 53 & 3 & 62 & 39 \\
\hline Mean age (years) b & $36.6 \pm 8.1$ & $36.2 \pm 12.3$ & $41.9 \pm 14.3$ & $34.5 \pm 10.8$ \\
\hline \multicolumn{5}{|l|}{ Marital status c (\%) } \\
\hline Single & 53 & 47 & 40 & 50 \\
\hline Married & 35 & 24 & 28 & 24 \\
\hline Widowed & 6 & 3 & 12 & I \\
\hline Separated & 6 & 25 & 20 & 25 \\
\hline Had children (\%) & 59 & 55 & 64 & 53 \\
\hline Physical illness or disability ${ }^{d}(\%)$ & 53 & 42 & 62 & 37 \\
\hline \multicolumn{5}{|l|}{ Mental health symptoms (\%) } \\
\hline Last year & 65 & 72 & 72 & 71 \\
\hline Last three months & 94 & 86 & 92 & 85 \\
\hline \multicolumn{5}{|l|}{ Visited general practitioner } \\
\hline during the last year (\%) & 79 & 86 & 91 & 84 \\
\hline during the last week (\%) & 6 & 3 & 6 & 13 \\
\hline Lifetime in-patient psychiatric treatment (\%) & 43 & 51 & 54 & 49 \\
\hline \multicolumn{5}{|l|}{ Method of index attempt (\%) } \\
\hline Violent & 0 & 9 & 6 & 9 \\
\hline \multicolumn{5}{|l|}{ Lethality of index attempt (\%) } \\
\hline Mild & 40 & 48 & 56 & 46 \\
\hline Intermediate & 20 & 31 & 19 & 33 \\
\hline Severe & 40 & 21 & 25 & 21 \\
\hline Used alcohol before the attempt (\%) & 71 & 65 & 66 & 65 \\
\hline Previous parasuicide (\%) & 47 & 51 & 50 & 48 \\
\hline Psychiatric consultation (\%) & 47 & 47 & 44 & 48 \\
\hline Beck Depression Inventory & $21.1 \pm 12.4$ & $20.8 \pm 10.6$ & $22.5 \pm 11.7$ & $20.3 \pm 10.4$ \\
\hline Beck Hopelessness Scale & $9.3 \pm 5.7$ & $9.0 \pm 5.1$ & $9.0 \pm 5.6$ & $9.0 \pm 5.0$ \\
\hline Beck Suicidal Intention Scale e & $14.5 \pm 7.7$ & $10.7 \pm 6.5$ & $12.2 \pm 7.1$ & $10.7 \pm 6.5$ \\
\hline Self Esteem Scale & $21.5 \pm 4.0$ & $22.5 \pm 2.5$ & $21.8 \pm 3.4$ & $22.6 \pm 2.4$ \\
\hline State Trait Anger Scale & $36.2 \pm 7.2$ & $35.2 \pm 9.0$ & $35.3 \pm 8.5$ & $35.2 \pm 9.0$ \\
\hline \multicolumn{5}{|l|}{ Recommended aftercare ${ }^{f}(\%)$} \\
\hline Nothing & 24 & 23 & 22 & 23 \\
\hline Outpatient & 76 & 56 & 60 & 57 \\
\hline Inpatient & - & 21 & 18 & 20 \\
\hline \multicolumn{5}{|l|}{ Suicide method (\%) } \\
\hline Drug overdose & 59 & & & \\
\hline Hanging & 18 & & & \\
\hline Shooting & 6 & & & \\
\hline Jumping from high place & 6 & & & \\
\hline Jumping under vehicle & 12 & & & \\
\hline
\end{tabular}

a Death (all causes) vs. survived Fisher's exact test, $\mathrm{p}=0.006$ b Death (all causes) vs. survived $F=3.9, \mathrm{df}=222, \mathrm{p}<0.00 \mathrm{I}$ c Death (all causes) vs. survived: widowed vs. other $\chi^{2}=10.3, \mathrm{df}=\mathrm{I}, \mathrm{p}=0.00 \mathrm{I}^{\mathrm{d}}$ Death (all causes) vs. survived Fisher's exact test, $\mathrm{p}=0.002$ e Suicide vs. not suicide $\mathrm{F}=$ $2.3, \mathrm{df}=22 \mathrm{I}, \mathrm{p}=0.02 \mathrm{f}$ Suicide vs. not suicide Likelihood ratio $\chi^{2}=7.8, \mathrm{df}=2, \mathrm{p}=0.02$

Suicide accounted for $34 \%$ of all deaths. There were no statistically significant differences in suicide rates or overall mortality between the four Finnish centres. $41 \%(\mathrm{~N}=$ 7) of the subjects completing suicide switched the suicide method to another. 21 attempters $(9 \% ; 11$ males and 10 females) had died by natural causes, 11 (5\%; 10 males and 1 female) had died by accidents and one male was murdered.
The cumulative survival curve plots for the 12-year followup appear in Figures 1 and 2 for each gender. The overall risk of death among males was significantly higher (log rank statistics 8.06, $\mathrm{df}=1, \mathrm{p}=0.0045$ ) (Figure 1 ). There was no statistically significant gender difference in suicide risk during the follow-up period (log rank statistics 0.75, $\mathrm{df}=1, \mathrm{p}=0.4)$ (Figure 2). 


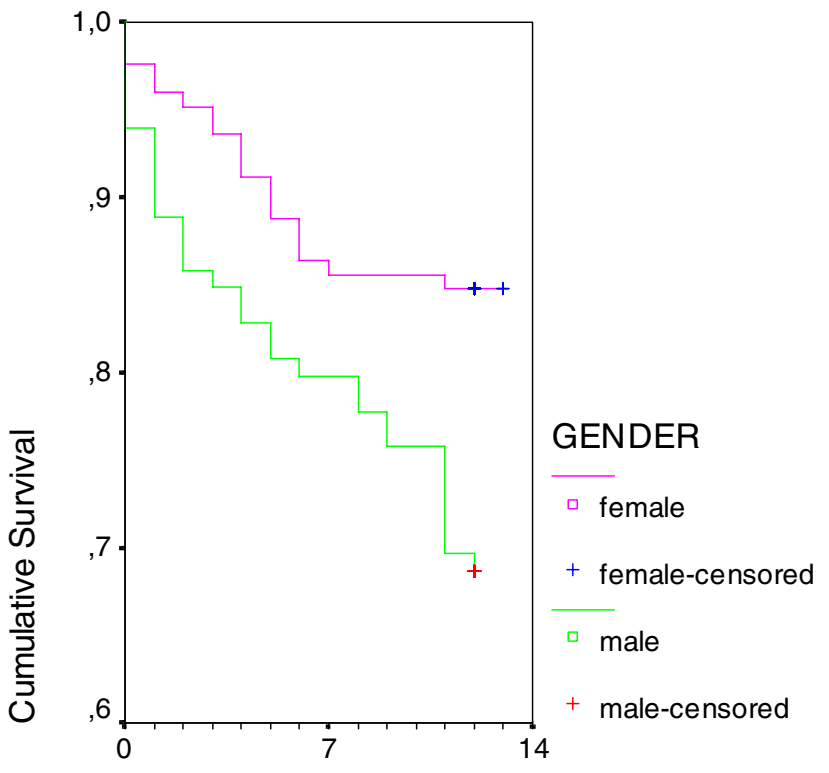

Time in years

\section{Figure I}

Cumulative proportion of patients surviving after index suicide attempt. Males have significantly less favourable prognosis than females. Censored cases are cases for which the event is not recorded = patients surviving. Kaplan-Meier survival curves: log rank statistics $8.06, \mathrm{df}=\mathrm{I}, \mathrm{p}=0.0045$.

Suicide attempters who eventually committed suicide had scored higher on Beck's Suicidal Intention Scale (Table 1). Reasons and motives for the suicide attempt appear in Table 2. Problems with partner, having wanted to die, and having wanted to make things easier for others were more common among those who committed suicide. Physical illness or disability and problems with partner were more common among suicide attempters who died (all causes) during the follow-up. High scores on Beck's Suicidal Intention Scale predicted suicide (Table 3). Male gender, older age, physical illness or disability and high scores on Beck's Suicidal Intention Scale predicted death (all causes) (Table 3).

\section{Discussion}

The findings of the present study confirm previous research suggesting that a high level of suicidal intent is a significant predictor of both subsequent death and suicide following a suicide attempt. Moreover, high suicidal intent scores at index attempt seem to be a more powerful predictor of eventual suicide than previous attempts or hopelessness.

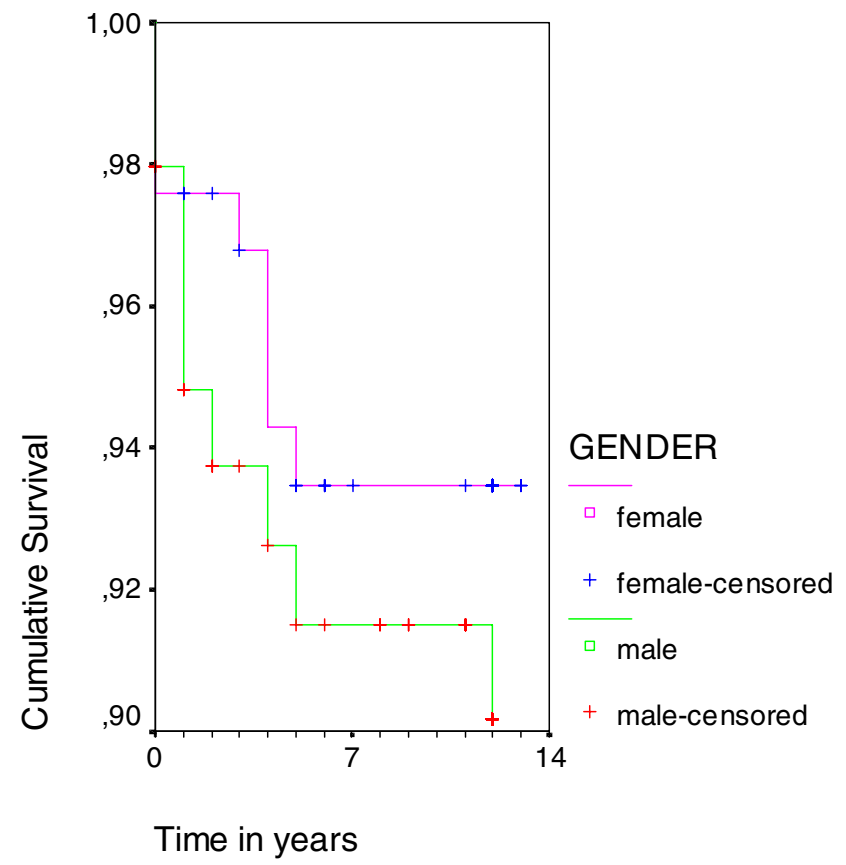

Figure 2

Cumulative proportion of patients not committing suicide after the index suicide attempt. No significant difference between males and females. Censored cases are cases for which the event is not recorded = patients not committing suicide. Kaplan-Meier survival curves: log rank statistics 0.75 , $\mathrm{df}=\mathrm{I}, \mathrm{P}=0.4$.

To our knowledge, this is the first follow-up study of attempted suicide in Finland to include regions beyond the capital area, and is thus more representative of the country as a whole than earlier studies. As no differences in mortality between the four regions emerged, our findings support the generalizability of our previous findings from Helsinki-based cohorts to other parts of the country. The extensive structured interview and case report method used in the present study is comprehensive and provides a broad picture of suicide attempters and their outcomes. Most previous studies have been based on hospital records only or have included only attempters referred for psychiatric consultation or attempts made by self-poisoning.

The disadvantage of an interview study is that some patients refuse to participate. In this study no significant differences were found in sociodemographic variables between the interviewees and the entire suicide attempt population [19]. The only statistically significant difference was that the male interviewees were more likely to have received psychiatric consultation than the other men in the entire parasuicide population [19]. Thus we cannot 
Table 2: Reasons and motives for the index suicide attempt.

\begin{tabular}{|c|c|c|c|c|}
\hline Variable & $\begin{array}{l}\text { Suicide } \\
(N=17)\end{array}$ & $\begin{array}{l}\text { Not suicide } \\
(N=207)\end{array}$ & $\begin{array}{l}\text { Death, all causes } \\
(N=50)\end{array}$ & $\begin{array}{l}\text { Survived } \\
(N=174)\end{array}$ \\
\hline \multicolumn{5}{|l|}{ Reasons why patient took pills or injured himself/herself (\%) } \\
\hline Problems with partner a & 33 & 61 & 44 & 63 \\
\hline Problems with parents & 38 & 34 & 38 & 34 \\
\hline Problems with children & 25 & 17 & 15 & 18 \\
\hline Problems with loneliness & 75 & 72 & 79 & 71 \\
\hline Problems in making or maintaining friendships and social relations & 50 & 46 & 49 & 46 \\
\hline Rejection by lover & 27 & 39 & 44 & 37 \\
\hline Physical illness or disability ${ }^{b}$ & 31 & 20 & 36 & 17 \\
\hline Mental illness and psychiatric symptoms & 50 & 69 & 64 & 68 \\
\hline Unemployment & 38 & 21 & 30 & 21 \\
\hline Addiction & 56 & 44 & 58 & 42 \\
\hline \multicolumn{5}{|l|}{ Motives for the suicide attempt (\%) } \\
\hline My thoughts were so unbearable & 77 & 74 & 70 & 76 \\
\hline I wanted to show someone how much I loved him/her & 31 & 36 & 36 & 36 \\
\hline I lost control over myself & 62 & 69 & 65 & 70 \\
\hline The situation was so unbearable & 79 & 76 & 77 & 77 \\
\hline I wanted to get away from an unacceptable situation & 62 & 59 & 60 & 59 \\
\hline I wanted others to know how desperate I felt & 39 & 54 & 42 & 56 \\
\hline I wanted to die c & 93 & 62 & 67 & 64 \\
\hline I wanted to get help from someone & 33 & 59 & 49 & 60 \\
\hline I wanted to know if someone really cared about me & 29 & 42 & 33 & 44 \\
\hline I wanted others to pay for the way they treated me & 29 & 27 & 30 & 26 \\
\hline I wanted to make someone feel guilty & 36 & 27 & 30 & 26 \\
\hline I wanted to persuade someone to change his/her mind & 21 & 26 & 14 & 29 \\
\hline I wanted to make things easier for others $d$ & 79 & 39 & 46 & 41 \\
\hline I wanted to sleep for a while & 54 & 44 & 40 & 46 \\
\hline
\end{tabular}

a Suicide vs. not suicide Fisher's exact test, $p=0.05$; Death (all causes) vs. survived Fisher's exact test, $p=0.05$ beath (all causes) vs. survived Fisher's exact test, $p=0.007$ c Suicide vs. not suicide Fisher's exact test, $p=0.02$ d Suicide vs. not suicide Fisher's exact test, $p=0.005$

exclude the possibility of overrepresentation of more severe cases in our initial parasuicide sample. However, our sample appears to be representative of those suicide attempters who are sufficiently motivated to stay in health care. The main limitation of the present study is that we were unable to use a structured diagnostic interview for all patients and thus could not include the DSM-diagnoses as possible risk factors. Previous studies have found that the vast majority of suicide attempters suffer from mental disorders [32-36]. However, there appears to be only one previous study with 30 months of follow-up using structured diagnostic information [37].

The overall mortality of suicide attempters was remarkably high, in accordance with previous studies [17,38-41]: a fifth of the cohort died during the 12-year follow-up. The risk for suicide ( $8 \%$ ) in the present study is consistent with the findings of a recent review of fatal repetition of self-harm [42]. Most previous studies have found significant gender differences in suicide and overall mortality after attempted suicide $[17,18,38,39,43-45]$. Somewhat surprisingly, we did not detect a statistically significant gender difference in suicide mortality in the present study.
We cannot, however, exclude the possibility that male suicide attempters who were more motivated to stay in health care and to participate in the interviews and psychiatric consultation were selected. It has been found that patients who discharge themselves before completing initial management have a considerably increased rate of repetition [46]. Furthermore, males with higher intent may have used more lethal methods and died rather than survived at an index attempt. Although the cohort was collected from several cities, the sample size remained moderate, and due to limited statistical power, we cannot rule out the possibility of gender differences in suicide mortality. However, male gender was a risk factor for death by all causes during the follow-up. These latter results accord with Nordentoft et al. [16], who found male gender to be a predictive factor for death by all causes, but not for suicide during a ten-year follow-up period in Denmark.

Previously, hopelessness has been found predictive of actual suicide, both in psychiatric outpatients [13] and in hospitalized suicide ideators [12]. However, these studies measured only hopelessness and depression, not level of 
Table 3: Risk factors for suicide and death (all causes) (Survival analysis: Cox regression models)

\begin{tabular}{|c|c|c|c|c|c|c|}
\hline \multirow[b]{2}{*}{ Risk factors } & \multicolumn{3}{|l|}{$\underline{\text { Suicide }}$} & \multicolumn{3}{|c|}{ Death, all causes } \\
\hline & OR & $95 \% \mathrm{Cl}$ & $P$ & OR & $95 \% \mathrm{Cl}$ & $P$ \\
\hline Male gender & & & & 3.04 & $1.56-5.94$ & 0.001 \\
\hline Age & & & & 1.04 & $1.02-1.07$ & 0.002 \\
\hline Beck Suicidal Intention Scale & 1.18 & $1.06-1.33$ & 0.004 & 1.06 & I.0I-I.II & 0.03 \\
\hline Physical illness or disability & 3.08 & $0.87-10.97$ & 0.08 & 2.22 & $1.10-4.49$ & 0.03 \\
\hline
\end{tabular}

suicidal intent. Furthermore, in a sample of hospitalized suicide attempters a diagnosis of alcoholism and the SIS Precautions subscale predicted eventual suicide [47], not hopelessness. In addition, Nimeus et al. [48] found in a similar sample of suicide attempters with different diagnoses that the Hopelessness Scale was an unsatisfactory instrument for predicting future suicide; hopelessness was better associated with mood disorders. On the other hand, in patients with affective disorders $[11,15]$ degree of hopelessness appeared to be an important factor predicting eventual suicide, although its significance may depend on the history of drug and alcohol abuse [49].

Very few follow-up studies after attempted suicide have used a comprehensive interview including known scales for assessing the severity of the attempt. Most follow-up studies have had small clinical samples or been large epidemiological studies without structured interview information. Thus, strongly significant risk factors for subsequent suicide, particularly high suicidal intent, may have remained undetected. Suicide attempters with high intent is a risk group of patients with high suicide and overall mortality, therefore various possibilities of surveillance may be considered. However, as the suicide risk remains high for decades, a more feasible approach might be focusing clinical attention to periods of likely elevated risk, such as episodes of depression.

\section{Conclusions}

In conclusion, the level of suicidal intent appears to be the most powerful predictor of eventual suicide after attempted suicide. As most previous parasuicide followup studies have not reliably measured level of suicide intent, its important role as a predictor of eventual suicide has remained largely unrecognised.

\section{Competing interests}

None declared.

\section{Authors' contributions}

JL conceived and designed the collection of the initial study sample. AO participated in conceiving and designing the collection of the initial study sample and coordinated the study. KS analysed the data of the present study and wrote the report. EI participated in writing the paper. All authors read and approved the final manuscript.

\section{Acknowledgements}

We are grateful to the interviewers: V. Granström, S. Heinonen, U. Mustonen, L. Rantanen, M-L Rasanen I. Sovijärvi and T. Viirre in Helsinki; J. Happonen, A Hytönen, E-L Männistö, E. Roivainen and J. Salkosalo in Jyväskylä; S Nikkanen and I Paasivirta in Rovaniemi; H Takala in Seinäjoki.

\section{References}

I. Harris EC, Barraclough B: Suicide as an outcome for mental disorders: a meta-analysis. Br J Psychiatry 1997, I 70:205-228.

2. Beck AT, Schuyler D, Herman I: Development of Suicidal Intent Scales. In The Prediction of Suicide Edited by: Beck AT, Resnick HLP, Lettieri DJ. Bowie, Maryland: Charles Press; 1974:45-56.

3. Pierce $D W$ : The predictive validation of a suicide intent scale: a five year follow-up. Br J Psychiatry I98I, I 39:39I-396.

4. Pallis DJ, Gibbons JS, Pierce DW: Estimating suicide risk among attempted suicides II. Efficiency of predictive scales after the attempt. Br J Psychiatry 1984, | 44: | 39-| 48.

5. Lönnqvist J, Tolppanen E-M: Outcome of attempted suicide. In Psychiatry - the state of the art Edited by: Pichot P, Berner P, Wolf R, Thau K. New York: Plenum Press; 1985:889-894.

6. Lönnqvist J, Ostamo A: Suicide following the first suicide attempt. A five-year follow-up using a survival analysis. Psychiatr Fenn 1991, 22:171-179.

7. Suokas J, Lönnqvist J: Outcome of attempted suicide and psychiatric consultation: risk factors and suicide mortality during a five-year follow-up. Acta Psychiatr Scand |99|, 84:545-549.

8. Linehan MM: Suicidal people: One population or two? In Psychobiology of Suicidal Behavior Ann NY Acad Sci 1986, 487: I6-33.

9. Beck AT, Weissman A, Lester D, Trexler L: The measurement of pessimism: the hopelessness scale. J Consult Clin Psychol 1974, 42:861-865.

10. Beck AT, Steer RA, Kovacs M, Garrison B: Hopelessness and eventual suicide: a 10 -year prospective study of patients hospitalized with suicidal ideation. Am J Psychiatry 1985, | 42:559-563.

II. Fawcett J, Scheftner W, Clark D, Hedeker D, Gibbons R, Coryell W: Clinical predictors of suicide in patients with major affective disorders: a controlled prospective study. Am J Psychiatry 1987, I 44:35-40.

12. Beck AT, Brown G, Steer RA: Prediction of eventual suicide in psychiatric inpatients by clinical ratings of hopelessness. J Consult Clin Psychol 1989, 57:309-310.

13. Beck AT, Brown G, Berchick RJ, Stewart BL, Steer RA: Relationship between hopelessness and ultimate suicide: a replication with psychiatric outpatients. Am J Psychiatry 1990, 147:190-195.

14. Weishaar ME, Beck AT: Hopelessness and suicide. Int Review Psychiatry 1992, 4:177-184.

15. Keller F, Wolfersdorf M: Hopelessness and the tendency to commit suicide in the course of depressive disorders. Crisis 1993, I4:173-177.

16. Nordentoft M, Breum L, Munck LK, Nordestgaard AG, Hunding A, Bjaeldager PAL: High mortality by natural and unnatural causes: a 10 year follow up study of patients admitted to a poisoning treatment centre after suicide attempts. BMJ 1993 , 306: $1637-164 \mid$. 
17. Hawton K, Fagg J: Suicide, and other causes of death, following attempted suicide. $\mathrm{Br}$ J Psychiatry 1988, I 52:359-366.

18. Suokas J, Suominen K, Isometsä E, Ostamo A, Lönnqvist J: Longterm risk factors for suicide mortality after attempted suicide - findings of a 14-year follow-up study. Acta Psychiatr Scand 200I, I04:II7-I2I.

19. Ostamo A, Rasanen L, Valjakka S, Lönnqvist ]: WHO/EURO Multicentre Study on Parasuicide: The repetition-prediction study in Finland. Materials and Methods Publications of the National Public Health Institute B I8/ 1995. Helsinki: Yliopistopaino; 1995.

20. Bille-Brahe U, Kerkhof A, De Leo D, Schmidtke A, Crepet $P$, Lönnqvist J, Michel K, Salander-Renberg E, Stiles TC, Wasserman D, Egebo $\mathrm{H}$ : A repetition-prediction study on European parasuicide populations. Part II of the WHO/Euro Multicentre Study on Parasuicide in cooperation with the EC concerted action on attempted suicide. Crisis 1996, 17:22-31.

21. Bille-Brahe U, Kerkhof A, De Leo D, Schmidtke A, Crepet $P$, Lönnqvist J, Michel K, Salander-Renberg E, Stiles TC, Wasserman D, Aagaard B, Egebo $H$, Jensen $B$ : A repetition-prediction study of European parasuicide populations: a summary of the first report from Part II of the WHO/EURO Multicentre Study on Parasuicide in co-operation with the EC Concerted Action on Attempted Suicide. Acta Psychiatr Scand 1997, 95:8I-86.

22. Schmidtke A, Bille-Brahe U, De Leo D, Kerkhof A, Bjerke T, Crepet $P$, Haring C, Hawton K, Lönnqvist J, Michel K, Pommereau X, Querejeta I, Phillipe I, Salander-Renberg E, Temesvary B, Wasserman D, Fricke S, Weinacker B, Sampaio-Faria JG: Attempted suicide in Europe: rates, trends and sociodemographic characteristics of suicide attempters during the period 1989-1992. Results of the WHO/EURO Multicentre Study on Parasuicide. Acta Psychiatr Scand 1996, 93:327-338.

23. World Health Organization: Working Group on Preventive Practices in Suicide and Attempted Suicide: Summary Report (ICPIPSF 017 (s) 6526 V) Copenhagen: WHO Regional Office for Europe; 1986.

24. Kerkhof AJFM, Bernasco W, Bille-Brahe U, Platt S, Schmidtke A: European Parasuicide Study Interview Schedule (EPSIS I). Version 5.I. In WHO/EURO Multicentre Study on Parasuicide. Facts and figures Edited by: Bille-Brahe U, Bjerke T, Crepet P, De Leo D, Haring C, Hawton K, Kerkhof A, Lönnqvist J, Michel K, Philippe A, Pommereau X, Querejeta I, Salander-Renberg E, Schmidtke A, Temesvary B, Wasserman D, Sampaio Faria J. Copenhagen: World Health Organization Regional Office for Europe; 1993:53-II8.

25. Spielberger CD: State-Trait Anger Expression Inventory. Research edition Odessa, Florida: Psychological Assessment Resources, Inc; 1988.

26. Rosenberg M: Society and the adolescent self-image Princeton: Princeton University Press; 1965.

27. Bancroft JHJ, Skrimshire AM, Simkin S: The reasons people give for taking overdoses. $\mathrm{Br}$ / Psychiatry 1976, I 28:538-548.

28. Bancroft JHJ, Hawton K, Simkin S, Kingston B, Cumming C, Whitwell $D$ : The reasons people give for taking overdoses: a further inquiry. Br J Modern Psychology 1979, 52:353-365.

29. Beck AT, Ward CH, Mendelson M, Mock J, Erbaugh J: An inventory for measuring depression. Arch Gen Psychiatry 196I, 4:56I-57I.

30. Statistics Finland: Causes of death 2002. Official Statistics of Finland, Health 2003: 2. Helsinki 2003.

31. Suomen säädöskokoelma: Laki kuolemansyyn selvittämisestä (459/ 1973). Helsinki 1997.

32. Beautrais AL, Joyce PR, Mulder RT, Fergusson DM, Deavoll B], Nightingale SK: Prevalence and comorbidity of mental disorders in persons making serious suicide attempts: a case-control study. Am J Psychiatry 1996, I 53:1009-1014.

33. Suominen K, Henriksson M, Suokas J, Isometsä E, Ostamo A, Lönnqvist J: Mental disorders and comorbidity in attempted suicide. Acta Psychiatr Scand I 996, 94:234-240.

34. Ferreira de Castro E, Cunha MA, Pimenta F, Costa I: Parasuicide and mental disorders. Acta Psychiatr Scand 1998, 97:25-31.

35. Haw C, Hawton K, Houston K, Townsend E: Psychiatric and personality disorders in deliberate self-harm patients. $\mathrm{Br} J$ Psychiatry 200I, 178:48-54.

36. Hawton K, Houston K, Haw C, Townsend E, Harris L: Comorbidity of axis $I$ and and II disorders in patients who attempted suicide. Am J Psychiatry 2003, 160: 1494-1500.

37. Beautrais A, Joyce $P$, Mulder R: Unmet needs following serious suicide attempt: follow-up of 302 individuals for $\mathbf{3 0}$ months. In Unmet Need in Psychiatry Edited by: Andrews, Henderson. Cambridge: Cambridge University Press; 1999:245-255.
38. Nordström P, Samuelsson M, Åsberg M: Survival analysis of suicide risk after attempted suicide. Acta Psychiatr Scand 1995, 91:336-340

39. Rygnestad T: A prospective 5-year follow-up study of self-poisoned patients. Acta Psychiatr Scand 1988, 77:328-331.

40. Ekeberg $O$, Ellingsen $O$, Jacobsen D: Suicide and other causes of death in a five-year follow-up of patients treated foe self-poisoning in Oslo. Acta Psychiatr Scand 1991, 83:432-437.

41. Beautrais AL: Subsequent mortality in medically serious suicide attempts: a $\mathbf{5}$ year follow-up. Aust NZ Psychiatry 2003, 37:595-599.

42. Owens $D$, Horrocks J, House A: Fatal and non-fatal repetition of self-harm. Systematic review. Br J Psychiatry 2002, I8I:193-199.

43. Ostamo A, Lönnqvist J: Excess mortality of suicide attempters. Soc Psychiatry Psychiatr Epidemiol 200I, 36:29-35.

44. Hawton K, Zahl D, Weatherall R: Suicide following deliberate self-harm: long-term follow-up of patients who presented to a general hospital. Br J Psychiatry 2003, I 82:537-542.

45. Suominen K, Isometsa E, Suokas J, Haukka J, Achte K, Lonnqvist J: Completed suicide after a suicide attempt: a 37-year followup study. Am J Psychiatry 2004, 161:562-563.

46. Crawford MJ, Wessely S: Does initial management affect the rate of repetition of deliberate self harm? cohort study. $B M$ 1998, I7(3):985.

47. Beck AT, Steer RA: Clinical predictors of eventual suicide: a 5to I0-year prospective study of suicide attempters. J Affect Disord 1989, 17:203-209.

48. Nimeus A, Träskman-Bendz L, Alsen M: Hopelessness and suicidal behavior. J Affect Disord 1997, 42:137-I44.

49. Young MA, Fogg LF, Scheftner WA, Fawcett JA: Interactions of risk factors in predicting suicide. Am J Psychiatry 1994, I 5 I:434-435.

\section{Pre-publication history}

The pre-publication history for this paper can be accessed here:

http://www.biomedcentral.com/1471-244X/4/11/pre pub

Publish with Biomed Central and every scientist can read your work free of charge

"BioMed Central will be the most significant development for disseminating the results of biomedical research in our lifetime. "

Sir Paul Nurse, Cancer Research UK

Your research papers will be:

- available free of charge to the entire biomedical community

- peer reviewed and published immediately upon acceptance

- cited in PubMed and archived on PubMed Central

- yours - you keep the copyright
BiolMedcentral 